7. Historia DEL PENSAMIENTO JURÍdICO 

Revista de Estudios Histórico-Jurídicos

[Sección Historia del Pensamiento Jurídico]

XXXVI (Valparaíso, Chile, 2014)

[pp. 367 - 383]

\title{
EL PODER HUMANO EN EL ESTABLECIMIENTO DEL DERECHO POSITIVO SEgÚN PEDRO de ARAgÓN. UN ESTUDIO SOBRE LA “DERIVATIO PER MODUM DETERMINATIONIS"
}

[The Human Power in the Establishment of the Positive Law According to Pedro of Aragon.

A Study on the "derivatio per modum determinationis"]

\author{
Sebastián Contreras Aguirre* \\ Universidad de los Andes, Santiago, Chile
}

\begin{abstract}
RESUMEN
En el presente trabajo se intenta exponer la lectura que hace Pedro de Aragón del problema de la determinación del derecho. El tema constituye uno de los tópicos centrales de la teología y filosofía del derecho de la Escuela de Salamanca. Con la aparición de las doctrinas protestantes, los pensadores de la Neoescolástica debieron presentar una respuesta para los muchos interrogantes que no tenían solución en el derecho divino y natural. Para esto recurrieron a Tomás de Aquino y a su doctrina de la derivatio per modum determinationis.

Palabras clave

Pedro de Aragón - Determinación de la ley natural - Ley positiva - Derivatio per modum determinationis.
\end{abstract}

\begin{abstract}
This work aims to put forward Pedro of Aragon's interpretation of the issue of determination in law. The subject is one of the main matters of theology and philosophy of law at the School of Salamanca. When the protestant doctrines were formulated, the Neo-Scholastic thinkers had to present responses for many questions raised that had no solution in divine and natural law. To do this, they resorted to Thomas Aquinas and his derivatio per modum determinationis doctrine.

KeYwords

Pedro of Aragon - Determination of natural law - Positive Law - Derivatio per modum determinationis.
\end{abstract}

RECIBIDO el 30 de mayo y ACEPTADO 1 de agosto de 2014

* Profesor en la Facultad de Derecho de la Universidad de los Andes. Dirección postal: Álvaro del Portillo 12455, Las Condes, Santiago, Chile. Correo electrónico: sca@miuandes.cl. El presente trabajo es el resultado de una investigación más amplia patrocinada por FONDECYT, proyecto $\mathrm{N}^{\circ} 3140035$. El autor agradece los comentarios del Prof. Dr. Joaquín García-Huidobro. 


\section{INTRODUCCIÓN}

Filósofo y jurista salmantino ${ }^{1}$, Pedro de Aragón nació en $1546^{2}$. Las noticias biográficas sobre este autor son más bien escasas y "con ciertas dudas en algunos puntos" ${ }^{3}$, por ejemplo: hasta ahora no se ha podido dar razón de su apellido, teniendo presente que sus padres fueron Antonio del Castillo e Inés Godínez Santisteban ${ }^{4}$.

En materia jurídica, se opuso a la tesis de los que distinguían tres clases de derecho5. Junto con esto, rechazó las ideas de Ulpiano y de algunos doctores antiguos que definían el derecho natural de manera zoológica. Esto porque dar culto a Dios y venerar a los padres es de derecho natural, y, sin embargo, no todos los animales lo hacen. Tal derecho no conviene a los animales más que metafóricamente ${ }^{6}$.

Entre los religiosos de su provincia, "Pedro de Aragón fue tenido en muy alto concepto" ". De hecho, se le pidieron tareas muy importantes, como ser uno de los cuatro padres examinadores de los que intentaban recibir grados en la orden de San Agustín, y formar parte de la comisión que debía defender públicamente las proposiciones teológicas de los agustinos en $1575^{\circ}$.

En el convento agustino de Tormes realiza sus estudios de artes, o sea, de filosofía, por alrededor de tres años ${ }^{9}$, al término de los cuales lo encontramos matriculado como estudiante de teología en Salamanca, para los cursos de 1564 a $1568^{10}$. En esos años la universidad salmantina "había alcanzado fama universal y los métodos de enseñanza de Francisco de Vitoria habían triunfado y sus doctrinas jurídico-morales se habían hecho comunes" ${ }^{11}$. Prueba de esto es la matrícula alcanzada por el Alma mater durante el curso 1566-1567: 7832 alumnos venidos

\footnotetext{
${ }^{1}$ López, José María, Doctrina de fray Pedro de Aragón acerca de la ley humano-positiva y efectos obligatorios de la ley penal, en Anuario de derecho penal y ciencias penales, 2 (1949), p. 242.

${ }^{2}$ Barrientos, José, Repertorio de moral económica (1536-1670) (Pamplona, EUnSA, 2011), p. 153. Se trata, en todo caso, de una fecha tentativa. También es posible que haya nacido en 1545 . Esta duda se debe a que, por entonces, no existían registros oficiales de bautismo o nacimiento.

${ }^{3}$ Belda Plans, Juan, La Escuela de Salamanca y la renovación de la teología en el siglo XVI (Madrid, Biblioteca de Autores Cristianos, 2000), p. 813.

${ }^{4}$ Barrientos, J., Repertorio de moral económica (1536-1670), cit. (n. 2), p. 153.

${ }^{5}$ Aragón, Pedro de, De justitia et jure, q. 57, a. 2.

${ }^{6}$ Ramírez, Santiago, El derecho de gentes. Examen critico de la filosofia del derecho de gentes desde Aristóteles hasta Francisco Suárez (Madrid, Stvdivum, 1955), p. 165.

${ }^{7}$ Jericó, Ignacio, La fe católica en los salmantinos del siglo XVI. Fray Luis de León, Juan de Guevara y Pedro de Aragón (Madrid, Agustiniana, 1999), p. 62.

${ }^{8}$ Ibíd., pp. 62-63.

${ }^{9}$ TACK, Theodoro, Fray Pedro de Aragón, OSA. His Life, Works, and Doctrine on Restitution (Chicago, Augustinian Press, 1957), p. 8.

${ }^{10}$ Belda Plans, J., La Escuela de Salamanca y la renovación de la teología en el siglo XVI, cit. (n. 3), p. 813.

${ }^{11}$ Barrientos, José, La injusticia en los juicios según Pedro de Aragón, en CRUZ, Juan (editor), La justicia y los juicios en el pensamiento del Siglo de oro (Pamplona, EUNSA, 2011), p. 51.
} 
de toda partes, lo que representa la mayor matrícula de Salamanca en los siglos XVI y XVII ${ }^{12}$.

Respecto de sus escritos, un asunto que todavía se discute es el grado de originalidad de sus comentarios a la Summa theologiae ${ }^{13}$. A pesar de que se le ha presentado como un simple compilador de las ideas de sus predecesores, lo que parece más conforme con la verdad es que Aragón no ha sido un mero recopilador de las enseñanzas de la Escuela, "sino que partiendo de un precioso material anterior, lo incrementa en cierta medida con sus propias elucubraciones y trabajo personal" 14 .

En este sentido, me pliego a las conclusiones de Theodoro Tack y Luis Martínez Fernández, quienes rechazan las imputaciones de Ehrle sobre el carácter de mero compilador del salmantino, defendiendo, por esta razón, la novedad y rigurosidad de su pensamiento acerca de la determinación del derecho natural.

Porque el agustino no fue un simple repetidor de la enseñanza escolástica ${ }^{15}$, sino un pensador con voz propia, es que pretendió esclarecer las ideas de la Escuela con brevedad y agudeza, tomando como punto de arranque las exposiciones de los grandes doctores medievales. En ocasiones le bastó con la autoridad del Aquinate, pero también a veces lo interpreta a partir de las lecciones de sus maestros en la orden de San Agustín ${ }^{16}$.

En cuanto al uso de las lecturas de otros maestros de la Escuela salmantina, es el mismo Aragón quien nos da habida cuenta de ello en sus prólogos, al decir que se ha servido para la confección de su obra de las lecciones de sus maestros y hermanos de religión, Juan de Guevara, fray Luis de León y Pedro de Uceda, lecciones de las que otros, sin pertenecer a su misma religión, se apoderaban de ellas sin citar su procedencia, cosa que Aragón no soportaba de buen grado ${ }^{17}$.

Por ende, Aragón no fue un servil seguidor de las ideas de Tomás, "sino que muestra independencia de criterio y sabe apartarse de él en algunas cuestiones particulares" ${ }^{18}$. En este agustino tenemos un buen intérprete de Tomás de quien abundan las citas. Hemos visto cómo acierta a exponer el verdadero pensamiento de aquél en algunos lugares, que podrían ofrecer duda y fueron ocasión de tropiezo para quienes no tienen en cuenta todo el sistema de un autor, para interpretar cualquier frase aislada ${ }^{19}$.

En este sentido, y como buen escolástico, "explica, aclara, explicita y amplía cuanto en santo Tomás está implícito o simplemente enunciado e, incluso,

${ }^{12}$ BarRientos, J., Repertorio de moral económica (1536-1670), cit. (n. 2), p. 154.

${ }^{13}$ Pena, Miguel Anxo, La Escuela de Salamanca. De la Monarquía hispánica al Orbe católico (Madrid, BAC, 2009), pp. 160-161.

${ }^{14}$ Barrientos, J., Repertorio de moral económica (1536-1670), cit. (n. 2), p. 159.

${ }^{15}$ Belda Plans, J., La Escuela de Salamanca y la renovación de la teología en el siglo XVI, cit. (n. 3), p. 815.

${ }^{16}$ BarRientos, J., La injusticia en los juicios según Pedro de Aragón, cit. (n. 11), p. 52.

${ }^{17}$ Barrientos, José, El Tratado "De justitia et jure" (1590) de Pedro de Aragón (Salamanca, EUSAL, 1978), p. 61.

${ }^{18}$ Barrientos, J., Repertorio de moral económica (1536-1670), cit. (n. 2), p. 159.

${ }^{19}$ CARRÓ, Venancio, La teología y los teólogos-juristas españoles ante la conquista de América (Salamanca, Biblioteca de Teólogos Españoles, 1951), pp. 332-333. 
introduce cuestiones y problemas nuevos" 20 . Es cierto, retoma una serie de conclusiones que eran ya patrimonio común de la Escolástica renacentista, pero no sin proponer alguna distinción o matiz donde le parece pertinente. Escribe sobre la base de la enseñanza de sus predecesores, pero no sin hacer presente sus preocupaciones personales y los problemas que está viviendo la España del siglo XVI. Reproduce las ideas de Tomás, pero siempre haciendo el esfuerzo por darles novedad y aplicación en los nuevos tiempos en donde le ha tocado desarrollar su tarea docente como catedrático de teología.

\section{LA DETERMINACIÓN DEL DERECHO NATURAL EN EL PENSAMIENTO ESCOLÁSTICO-SALMANTINO}

Así como las normas del ius gentium se derivan del derecho natural, así también las normas positivas se derivan del ius naturae ${ }^{21}$. El proceso en que se originan estas normas es el que Tomás de Aquino reconoce como determinación, es decir, como la especificación de unas ideas comunes, los prima principia de la ley natural, en unas condiciones particulares de lugar y tiempo ${ }^{22}$.

El derecho "determinado" no es el resultado de una derivación conclusiva desde los principios naturales. Se origina, no por deducción, sino por la intermediación de la autoridad pública, que relaciona un principio natural con una premisa que añade según las características de su comunidad. A causa de lo anterior, el derecho "determinado" no equivale a un orden de justicia necesario y universal, sino a lo justo contingente, que está sujeto al cambio, y cuya función es concretar los preceptos indeterminados del derecho natural y divino.

Sobre esta base se sostiene que las normas obtenidas por vía de determinación, se derivan, no por consideraciones especulativas acerca de lo bueno o lo malo moral, sino por medio de razonamientos prácticos que toman en cuenta las distintas circunstancias en las que se realiza la acción. Luego, en la determinación no se trata de conocer un único modo de actuar que sea correcto, sino de decidir un modo de obrar adecuado para la comunidad de que se trate, esto es, de elegir uno entre los muchos medios disponibles para lograr un mismo fin ${ }^{23}$.

Pese a que no se trata de reglas necesarias, las normas positivas, al igual que los preceptos naturales, siempre obligan a culpa (es decir, en conciencia) y deben tenerse como dictadas por el mismo Dios. De ahí que los pensadores de la Escuela salmantina hayan señalado que quienes transgreden las normas del derecho positivo deben tenerse por injustos ${ }^{24}$, y se les debe aplicar las sanciones y penas que, libremente, haya establecido la autoridad para esos casos.

La libertad del gobernante puede verse, a mi juicio, en el hecho de que éste

\footnotetext{
${ }^{20}$ Barrientos, J., Repertorio de moral económica (1536-1670), cit. (n. 2), p. 159.

${ }^{21}$ PeÑa, Juan de la, De justitia, q. 57, a. 2, ms. T19.

${ }^{22}$ Aquino, Tomás de, Summa theologiae, I-II, q. 95, a. 2.

${ }^{23}$ Contreras, Sebastián, Los teólogos agustinos del siglo XVI sobre la "derivatio per modum determinationis": Juan de Guevara, Luis de León y Pedro de Aragón, en Cuestiones Teológicas, 40 (2013) 94, p. 382.

${ }^{24}$ Corpus Christi, Mancio de, De dominio, tertia pars, notanda.
} 
puede convertir en lícito lo que sin su intervención no estaría sino en contra del derecho por naturaleza, aunque no como si el derecho humano pudiese prejuzgar contra el derecho natural derogándolo en algún punto, sino porque puede poner, por parte del objeto, una circunstancia en virtud de la cual deje de ser de derecho natural lo que lo sería si no existiese esa circunstancia ${ }^{25}$.

Esto equivale a decir que las leyes positivas se justifican por la variedad de asuntos que no han quedado regulados por lo justo natural. En efecto, respecto de ciertas materias hay una indiferencia en cuanto a lo que es propio de la naturaleza humana, "y desde esa indiferencia e indeterminación se entiende la múltiple diversidad de formas que adquiere lo que es propio del derecho positivo" ${ }^{26}$. Las autoridades, sin embargo, no pueden convertir en lícita una acción que es contraria al orden de la justicia, porque el orden de la recta razón es la causa y raíz de la juridicidad de las normas del derecho humano ${ }^{27}$.

Sentado lo anterior, el acto de determinación no puede ser considerado como una simple traslación de los principios naturales a una sociedad particular. Esto sería tanto como pensar la tarea legislativa (o la judicial, por ejemplo) como una simple aplicación teoremática de los preceptos naturales ${ }^{28}$. El derecho "determinado" resulta de un proceso hermenéutico-constructivo que lleva a cabo el gobernante, y que, según Hervada, se explica de la siguiente manera: partiendo de la verdad de los principios naturales, la prudencia jurídica modela una verdad futura (una regla de justicia) y la impone como obligatoria ${ }^{29}$. Este fenómeno constitutivo no es una forma de creatio ex nihilo. Dicha tarea se origina en la justicia objetiva y universal de las nomas naturales, que son el fundamento mediato de su obligatoriedad.

Todo lo expuesto se puede resumir, me parece, diciendo que el acto de determinación opera siempre que la ley humana contiene algo que no se deduce desde el derecho natural, esto es, siempre que la voluntad del legislador ha intervenido en el desarrollo de lo que es justo según la naturaleza del hombre y de la sociedad. Así, y por un acto de su voluntad ajustada a la razón, se establecen reglas de justicia "no necesarias", pero que, no obstante, son obligatorias en el foro de la conciencia. Sólo así se entienden las enseñanzas de los pensadores salmantinos en orden a definir que, una vez que el gobernante ha dictado una norma de justicia positiva, entonces hacer eso justo y omitirlo es injusto.

La determinación es, entonces, una realidad inevitable. El elemento discre-

${ }^{25}$ Molina, Luis de, De justitia et jure, I, disp. 4, 9.

${ }^{26}$ Zorroza, Idoya, Fundamentos morales del contrato y de la propiedad en Domingo de Soto, en Cruz, Juan (editor), La ley natural como fundamento moral y jurídico en Domingo de Soto (Pamplona, EUNSA, 2007), p. 215. En este sentido, cuando una cosa no sólo no es contraria al derecho natural, sino que además es conveniente según el tiempo y el lugar, en este caso la voluntad humana puede hacer que lo que se estableció sea justo. Y, en este caso, como dijo Aristóteles, lo que antes no expresaba nada, desde ese momento lo expresa.

${ }^{27}$ Guevara, J., De Justitia, q. 57, a. 3.

${ }^{28}$ Contreras, Sebastián, Santo Tomás y la doctrina de la determinación del derecho. Análisis de los textos tomistas, en Ciencia Tomista, 140 (2013) 450, pp. 90 ss.

${ }^{29}$ HeRVADA, Javier, Reflexiones acerca de la prudencia jurídica y el derecho canónico, en Revista Española de Derecho Canónico, 16 (1961), p. 427. 
cional en materia de justicia existe ahí donde hay sociedades y grupos humanos. Puesto que los hombres no viven al nivel de la ley eterna, ni siquiera en una hipotética sociedad de santos podríamos sustraernos a este ejercicio constructivo que se llama determinación.

\section{El derecho natural en Pedro de Aragón}

El gobierno del mundo, ley eterna, se manifiesta en las cosas de acuerdo con su naturaleza propia. Al ser el hombre un ser racional y libre, dicho principio de orden no existe en la vida humana al modo de las leyes físicas, que representan una necesidad absoluta, sino de manera libre, puesto que la creatura racional es providente para sí misma ${ }^{30}$.

A esta forma de participación del gobierno divino en el hombre se le ha llamado ley natural ${ }^{31}$. Esta ley, que la creatura racional conoce a partir de aquellas realidades que ha recibido como inclinaciones primarias, determina el orden moral de la vida social y política. Sus principios son, entonces, la raíz de la racionalidad de todas las decisiones humanas.

Dicha ley se encuentra impresa, inscrita, en el interior del hombre. Pero no se puede confundir con la potencia intelectiva o razón, ni es tampoco esencialmente un hábito, sino que la ley natural son unas proposiciones y principios prácticos evidentes en sí mismos. No porque nuestro entendimiento práctico no necesite de alguna facultad o virtud para conocerlos, sino porque no necesita de otros principios $^{32}$.

Tales proposiciones o principios proceden de la naturaleza. De esta manera, señala Aragón que la verdadera definición del derecho natural es aquella que lo restringe sólo a la vida humana ${ }^{33}$. En este sentido, este derecho está contenido en los primeros principios de la ley natural y en las conclusiones de ellos deducidas absoluta y necesariamente ${ }^{34}$. Por lo cual erró Domingo de Soto al decir que dichas conclusiones pertenecen al derecho de gentes, pues de ahí se seguiría que los preceptos morales del Decálogo corresponden a ese derecho y serían abrogables como él, lo cual es un absurdo manifiesto ${ }^{35}$.

Cuando se dice que el derecho natural obliga a todos y es invariable, esto se ha de entender en cuanto a los primeros principios, pues las consecuencias y aplicaciones de estos principios "son variables por especiales circunstancias, aunque generalmente obliguen siempre y a todos" 36 . Por este motivo, en cuanto a los preceptos deducidos inmediatamente de los prima principia, la ley natural es casi

\footnotetext{
${ }^{30}$ Aragón, P., De justitia et jure, q. 57, a. 2.

${ }^{31}$ Ibíd., q. 85, a. 1.

${ }^{32}$ Barrientos, J., El tratado "De justitia et jure", cit. (n. 17), p. 119.

${ }^{33}$ Aragón, P., De justitia et jure, q. 57, a. 3.

${ }^{34}$ Ramírez, S., El derecho de gentes, cit. (n. 6), p. 165.

${ }^{35}$ Ibíd., pp. 165-166. Admitir la explicación sotiana equivaldría a aceptar que cualquier república perfecta podría terminar con esos principios. Véase: CARPINTERo, Francisco, Justicia y ley natural: Tomás de Aquino, y los otros escolásticos (Madrid, Publicaciones de la Universidad Complutense, 2004), pp. 176-177.

${ }^{36}$ Aragón, P., De justitia et jure, q. 57, a. 2.
} 
siempre recta y justa, aunque no siempre; lo cual indica que los juicios o preceptos deducidos de los primeros principios prácticos pueden fallar en su rectitud, pues para determinar si una acción concreta es buena o no hay que considerar todas las circunstancias. Así, del principio general "lo que no quieras para ti no lo hagas a otro" se concluye "statim" y necesariamente que no se debe tomar ni retener lo ajeno cuando el dueño se opone a ello razonablemente; y por tanto, hay que devolver lo que se tiene en depósito; pero si el dueño del depósito reclama esto para hacer algo en perjuicio suyo o de los demás, o que es en sí intrínsecamente malo, entonces, por razón de esa circunstancia concreta, lo que en sí mismo era recto se hace malo ${ }^{37}$.

Pese a que se trata de verdades morales inmutables y necesarias, que ordenan lo intrínsecamente bueno y rechazan lo intrínsecamente malo ${ }^{38}$, los principios naturales no representan un pliego de enunciados puramente especulativos y abstractos. Ante todo, son el signo de un derecho natural realista, que se funda en aquello que es más concorde con la razón y que se caracteriza por una apertura hacia lo histórico ${ }^{39}$.

\section{LA DETERMINACIÓN DEL DERECHO NATURAL SEgún Pedro de Aragón}

\section{El "De Justitia et jure".}

A diferencia del derecho natural, que establece lo que es adecuado al hombre per se, el derecho positivo o humano determina lo que es justo por la pura voluntad del legislador, en función del recto gobierno de una república determinada y para un tiempo determinado ${ }^{40}$. En este sentido, no hay inconveniente en que ciertas materias empiecen a ser justas por la pura voluntad de los hombres, en la medida que las leyes positivas regulan los detalles de la acción no cubiertos por el derecho natural.

Esto quiere decir que la ley positiva determina lo que en el derecho natural es sólo un principio general. De ahí que, en opinión de Aragón, lo que se manda en la ley humana no es por esencia bueno y justo sino sólo porque ha sido mandado, a diferencia de lo que está bajo el derecho natural, que es siempre bueno y necesario para conseguir la perfección moral.

Ejemplos de derecho positivo o "determinado" son, según la enseñanza de Aragón, los siguientes: la especificación de una pena concreta ${ }^{41}$, el modo en que se ha de dividir el tesoro en un campo ${ }^{42}$ y la determinación de las formalidades que se han de cumplir en los juicios ${ }^{43}$. Estas acciones no han sido ordenadas por

\footnotetext{
${ }^{37}$ Barrientos, J., El tratado “De justitia et jure”, cit. (n. 17), p. 123.

${ }^{38}$ Aragón, P., De justitia et jure, q. 57, a. 3.

${ }^{39}$ Riaza, Román, La Escuela española de Derecho Natural, en Universidad, 2 (1995), pp.

${ }^{40}$ Aragón, P., De justitia et jure, q. 60, a. 5.

${ }^{41}$ Ibíd., q. 85, a. 1.

${ }^{42}$ Ibíd., q. 66, a. 5.

${ }^{43}$ Ibíd., q. 67, a. 2.
} 325-327. 
el derecho natural, sino solamente por la ley humana, la que, en función del bien común, habrá de elegir de las muchas alternativas, la que sea más conveniente para la sociedad de que se trate ${ }^{44}$.

El resultado de la determinación no es ya un derecho natural puro ni tampoco una norma natural positivada (que sería el derecho de gentes), sino solo lo justo instituido arbitrariamente, un conjunto de normas-complemento que surgen a partir de la libre inventiva del legislador humano, aunque dentro de los márgenes de la razonabilidad práctica. Tales normas no reciben, al menos no directamente, su fuerza obligatoria desde los primeros principios del orden práctico, sino solo de su autor, el legislador humano, que ejerce un verdadero poder normativo, aunque limitado ${ }^{45}$.

Las leyes positivas humanas se subordinan a la ley natural y de ella se derivan, aunque no por consecuencia necesaria, o por modo de conclusión, sino por modo de especificación o concretización. Tales son las leyes que establecen penas contra los malhechores. Éste es el ejemplo que propone Tomás de Aquino en S.Th. I-II,95,2: el castigo de los culpables es de derecho natural, pero el determinar la clase de penas aplicables pertenece a la ley positiva humana, derivándose, por consiguiente, de las naturales por arbitrio y disposición del hombre y no de un modo necesario, y estando, desde luego, conformes siempre con el derecho natural del cual dimanan. Por esto, tales leyes no son de derecho natural, sino de derecho positivo humano. Las mismas ideas repiten otros muchos autores para demostrar la relación de subordinación en que se encuentra la ley positiva respecto de la natural ${ }^{46}$.

Supuesto que la ley positiva puede crear contenidos de justicia originariamente inexistentes por derecho natural, se sigue que los gobernantes, al prescribir algo, no sitúan la rectitud de lo mandado en el objeto del acto, sino sólo instalan la obligación de que eso se haga ${ }^{47}$. Y así, pueden estarse al mismo tiempo estas dos cosas: que todo acto preceptuado por la ley humana sea conforme a la razón por su propia naturaleza, y también que ese acto no pertenezca a la ley natural, sino a la ley humana, "puesto que la obligación de hacerlo nació de la ley humana solamente. En efecto, no estamos obligados a hacer todo lo que es concorde con la razón, y, sin embargo, estamos obligados a hacerlo sólo cuando lo preceptúa la ley humana" 48 .

El acto de determinación consiste, por ende, en el paso de unos pocos principios naturales, simples e imperfectos, a unas reglas de justicia complejas y determinadas según el éthos de cada sociedad, en una forma de arte que tiene como finalidad hacer más concretas aquellas verdades indeterminadas de la ley natural. Solo así

\footnotetext{
${ }^{44}$ Contreras, S., Los teólogos agustinos, cit. (n. 23), p. 393.

${ }^{45}$ Contreras, Sebastián, La derivación del derecho positivo desde el derecho natural en Tomás de Aquino. Un estudio a partir de "Summa Theologiae" y "Sententia libri Ethicorum", en Teología y Vida, 54 (2013), p. 682.

${ }^{46}$ López, J., Doctrina de fray Pedro de Aragón acerca de la ley humano-positiva y efectos obligatorios de la ley penal, cit. (n. 1), p. 245.

${ }^{47}$ Contreras, S., Los teólogos agustinos, cit. (n. 23), pp. 375-404.

${ }^{48}$ LeÓn, Luis de, De lege, q. 6, a. 2.
} 
se explican las palabras de Tomás de Aquino en orden a señalar que "todo juicio de la razón práctica se funda en ciertos principios naturalmente conocidos” ${ }^{4}$.

Este acto de determinación representa no sólo un movimiento de la inteligencia, que conoce el bien moral, sino también un acto de la voluntad. En concreto, Aragón señala que se trata de un "doble acto" del apetito: mientras que la inteligencia determina lo que es conveniente para la comunidad de conformidad con su éthos particular, la voluntad elige lo señalado (como simple indicación) por la razón y lo impone como obligatorio, es decir, lo impera ${ }^{50}$. El imperio tiene tal relevancia en la determinación del derecho natural, que Aragón escribe que la ley no obliga sin el debido imperium, y que una ley que no obliga no es verdadera ley: la obligación constituye su elemento distintivo ${ }^{51}$.

En la determinación, la autoridad debe ajustar sus decisiones a los principios del derecho natural. Este poder normativo del derecho natural procede de la ley eterna $^{52}$. De hecho, Aragón sostiene que de la razón divina reciben como de su fuente y fundamento la fuerza obligatoria las leyes humanas, porque la autoridad política es una causa segunda que está subordinada a la ley eterna, de la cual todas las decisiones de la autoridad reciben su fuerza normativa ${ }^{53}$. Esto refuerza, creo, el carácter obligatorio de cada determinación del gobernante. La transgresión de sus determinaciones, puesto que su potestad deriva de la ley eterna por medio de la ley natural, representa una transgresión mediata del derecho divino ${ }^{54}$, precisamente porque contraviene el principio fundamental de la vida social y política: los ciudadanos, por ley natural, deben obedecer a sus autoridades.

En su afirmación del carácter obligatorio de las leyes humanas, Aragón seguía la doctrina de fray Luis de León. En opinión de este autor, todo lo que manda la ley humana, una vez mandado, pertenece a la ley natural. Primero, porque una vez mandado, tiene condición de justo y bueno, necesario para conservar la virtud. Segundo, porque la ley natural, nacida de la inclinación natural que tiene el hombre a la vida civil y política, manda que el hombre obedezca al Estado o al que lo representa, ya que sin esta obediencia no puede durar la vida política ${ }^{55}$.

Supuesta esta potestad de las leyes humanas para obligar en conciencia, Aragón busca el fundamento de ello, y lo pone, no en la voluntad sola del legislador, sino en cuanto esta voluntad se subordina a la potestad divina y a la ley eterna, a seme-

${ }^{49}$ Aquino, T., Summa theologiae, I-II, q. 100, a. 1.

${ }^{50}$ Aragón, P., De justitia et jure, q. 62, a. 3. La ley es, en este sentido, un imperio de la voluntad.

${ }^{51}$ Barrientos, J., El tratado “De justitia et jure", cit. (n. 17), p. 135. Ahora bien, como se trata de principios de justicia derivados, la obligación de las leyes positivas no procede solamente de la voluntad del príncipe, aunque ésta sea la causa directa de su obligatoriedad. Tampoco se fundamenta exclusivamente en la materia sobre la que tratan. El origen de su condición de obligatorias ha de ser colocado tanto en la voluntad del legislador como en la naturaleza de la materia ordenada, que no es otra que aquello que resulta necesario para la consecución del bien social.

${ }^{52}$ Barrientos, J., El tratado “De justitia et jure”, cit. (n. 17), p. 120.

${ }^{53}$ Aragón, P., De justitia et jure, q. 62, a. 3.

${ }^{54}$ Barrientos, J., El tratado “De justitia et jure”, cit. (n. 17), p. 159.

${ }^{55}$ LEÓN, Luis de, De Lege, q. 5, a. 3. 
janza de lo que ocurre con todas las causas segundas con relación a sus efectos ${ }^{56}$. $\mathrm{Y}$ de esta manera, concluye: del mismo modo que en el orden natural las causas segundas producen sus efectos no absolutamente y por sí mismas, sino en cuanto reciben el influjo o moción de la causa primera, así también en el orden natural, la potestad humana, que es como las causas segundas, produce sus efectos, uno de los cuales es obligar a los hombres en conciencia a su observancia y cumplimiento, no absolutamente y por sí misma, sino en cuanto está subordinada a la potestad divina y a la ley eterna ${ }^{57}$.

\section{Los comentarios a "De conciliis".}

Las ideas de Pedro de Aragón destacaron especialmente en el campo de la eclesiología ${ }^{58}$. Sus enseñanzas sobre las potestades legislativas de la Iglesia fueron conservadas en el Tractatus de conciliis, contenido en sus comentarios a la II-II de la Summa theologiae de Tomás de Aquinbo.

En opinión del agustino, pertenece a la Iglesia tanto el poder de interpretar la Sagrada Escritura como la facultad para determinar todo aquello que diga relación con el gobierno del Pueblo de Dios ${ }^{59}$. Esto es lo que se conoce como potestad de jurisdicción ${ }^{60}$, que, según escribe, las autoridades de la Iglesia ejercen "a veces poniendo leyes y castigando, a veces enseñando la fe verdadera y determinando" ${ }^{6}$.

Las leyes dispuestas por la autoridad, que pueden tener una verdadera función constitutiva $^{62}$, no pueden ser contrarias al texto revelado ${ }^{63}$ o a la ley natural ${ }^{64}$. Luego, las normas que resultan de la determinación no son por su naturaleza principios de justicia per $s e^{65}$, sino sólo preceptos contingentes y cambiantes ${ }^{66}$, que están llamados a especificar lo que permanece inconcluso en el derecho natural. Se trata, en este sentido, de principios que no son buenos en sí mismos, pero que la Iglesia ha establecido para la regulación de las relaciones entre los fieles cristianos ${ }^{67}$.

Se trata, asimismo, de reglas necesarias para la regulación de la vida en sociedad $^{68}$. Esto porque, según apunta Aragón, obrar moralmente bien, sea largo

${ }^{56}$ López, J., Doctrina de fray Pedro de Aragón acerca de la ley humano-positiva y efectos obligatorios de la ley penal, cit. (n. 1), p. 248.

${ }^{57}$ Aragón, P., De justitia et jure, q. 62, a. 3.

${ }^{58}$ Horst, Ulrich, Papst, Konzil, Unfehlbarkeit. Die Ekklesiologie der Summenkommentare von Cajetan bis Billuart (Mainz, Matthias-Grünewald, 1978), pp. 149-157.

${ }^{59}$ Por este motivo, observa Aragón que no todas las cosas dispuestas por la Iglesia pertenecen al derecho divino. Algunas de ellas son de derecho humano.

${ }^{60}$ Aragón, Pedro de, In secundam secundae. De conciliis, 1, n. 64.

${ }^{61}$ Ibíd. En este sentido, señala Aragón que, por pertenecer a la Iglesia el cuidado del bien del hombre, "tiene ella tanto la potestad de dar leyes que corresponden a la utilidad y a la comodidad de la religión como la de castigar también a los transgresores de ellas”.

${ }^{62}$ I bÁNẼEZ, Andrés, La doctrina sobre la tradición en la Escuela Salmantina (siglo XVI) (Vitoria, Editorial Eset, 1967), p. 299.

${ }^{63}$ Vitoria, Francisco de, In secundam secundae, ms. 43, p. 55.

${ }^{64}$ Aragón, P., In secundam secundae, p. 312a.

${ }^{65}$ Aragón, P., In secundam secundae. De conciliis, 2, n. 66.

${ }^{66}$ Ibíd., 1, n. 64.

${ }^{67}$ VITORIA, F., In secundam secundae, ms. 43, pp. 58-59.

${ }^{68}$ Aragón, P., In secundam secundae, p. $267 \mathrm{~b}$. 
tiempo o siempre, es obra de un hombre sano y robusto según la razón. Ahora bien, el hombre quedó herido por el pecado y permanece en estado de debilidad y enfermedad ${ }^{69}$.

Por ende, el hombre no puede obrar largo tiempo moralmente bien por sus propias fuerzas ${ }^{70}$. Necesita de las leyes positivas, tanto humanas como divinas ${ }^{71}$.

Un ejemplo especialmente tratado por el agustino en materia de determinación, es el que se refiere a la cantidad de testigos que deben concurrir en los testamentos abiertos. Según enseña, la ley divina nada dice acerca del número de testigos que deben participar en los testamentos ${ }^{72}$. La ley positiva, en cambio, dispone rigurosamente las formalidades que se han de llevar en este tipo de convenciones, sin las cuales dicho negocio se reputaría inexistente ante el derecho.

Las leyes que resultan del acto de determinación son obligatorias a causa de la propia naturaleza del hombre, que es, a la vez, vegetativa, sensitiva y racional ${ }^{73}$. De esto resulta que, como el que tiene la parte vegetativa por Dios a la que corresponde conservar al individuo y la especie, le fue preciso someterse a los preceptos pertinentes a la generación, tanto a comer como a beber. Y por tener él la parte sensitiva que corresponde a las pasiones (se refiere al hombre), le fue necesario someterse a los preceptos pertinentes a la ira, al temor y a las restantes pasiones.

Por último, por tener la parte racional en la que están la voluntad y el entendimiento, le fue preciso al hombre someterse efectivamente a los preceptos de la justicia e injusticia, tanto los que proceden del derecho divino como los que han sido establecidos por las autoridades humanas ${ }^{74}$.

\section{LAS LIMITACIONES AL DOMINIO \\ Y LA DETERMINACIÓN DEL DERECHO NATURAL}

En opinión de Aragón, la autoridad política puede, en ciertas circunstancias, limitar mediante la ley la libre disposición de los bienes ${ }^{75}$. Aún más, puede transferir el dominio a otros, y contra la voluntad del dueño, "lo cual parece indicar la posibilidad de una expropiación forzosa, siempre que el bien común así lo exija"76. La razón que aduce el agustino es ésta: el hombre es por naturaleza social, pero la vida social de los hombres no puede darse sin una autoridad que proteja el bien

${ }^{69}$ Ibíd.

${ }^{70}$ Ibíd., In secundam secundae, p. $267 \mathrm{~b}$.

${ }^{71}$ Aquino, T., Summa theologiae, I-II, q. 95, a. 1.

${ }^{72}$ Aragón, P., In secundam secundae. De conciliis, 2, n. 66. Los principios divinos y naturales "solamente establecieron que si la malicia de los hombres no creciera excesivamente, el testimonio de dos o tres bastaría; pero una vez pervertida la fidelidad y justicia humana, el mismo derecho natural persuade que se exijan testimonio más firmes, como sucede en los testamentos, en que una vez fallecido el testador ya no puede manifestar su voluntad". BarRIENTOS, J., La injusticia en los juicios según Pedro de Aragón, cit. (n. 11), p. 72.

${ }^{73}$ Aragón, P., In secundam secundae, p. 255b.

${ }^{74}$ Ibíd.

${ }^{75}$ Aragón, Pedro de, De dominio, p. 138a. En cuanto a sus comentarios al De dominio, sigo la paginación de la edición de 1590 .

${ }^{76}$ Barrientos, J., El tratado “De justitia et jure”, cit. (n. 17), p. 243. 
común y sea administradora de justicia ${ }^{77}$. Por eso se hace legítima la intervención del Estado, ya sea para prohibir que los menores de edad enajenen sus bienes, haciendo que sus contratos sean nulos ${ }^{78}$, ya sea para reclamar para sí parte de los bienes de los ciudadanos ${ }^{79}$.

Así como el Estado puede, en justicia, privar de la vida a uno de sus ciudadanos cuando esto sea pertinente, así también puede privarle de sus bienes contra su voluntad, disponiendo de ellos por causa del bien social. Esto se explica porque el derecho natural manda que la vida política se encuentre ordenada y en paz. Por ende, cuando el bien social lo exige, es de derecho natural que las autoridades humanas establezcan las limitaciones al dominio que más convengan para su comunidad.

Estas limitaciones a la propiedad pueden ser de dos tipos. En primer lugar, pueden consistir en inhabilidades absolutas, como sucede en los menores de edad. En estos casos, el convenio pactado en contravención de las leyes del Estado es nulo y no puede hacerse válido, y en este sentido no transfiere el dominio ni en el fuero interno ni en el externo ${ }^{80}$. En segundo lugar, las limitaciones al dominio pueden revestir la forma de solemnidades sine qua non, por cuya ausencia el convenio pactado también se hace nulo y no transfiere el dominio en el fuero de la conciencia ${ }^{81}$.

Para analizar este problema, Aragón circunscribe su investigación al ejemplo de los testamentos. Supuesta la voluntad libre del testador, se pregunta si uno de estos negocios que adolece de algún vicio formal transfiere o no el dominio según lo dispuesto por el testador. A pesar de que reconoce la existencia de una doctrina favorable a la idea de que sí se transfiere el dominio en esos casos, lo que convence más al agustino es el hecho de que un negocio nulo por el derecho positivo no transfiere el dominio en el fuero de la conciencia, aunque el testador haya manifestado libre y conscientemente su voluntad de traspasar a otros la disposición de sus bienes ${ }^{82}$.

Esto se debe a que, tal como sucede en la realización de un artefacto, el que no existe formalmente mientras no esté plenamente determinado ${ }^{83}$, así también no existe el acto jurídico, testamento en este caso, si el testador no ha ajustado su manifestación de voluntad a las determinaciones del legislador. Y la razón es la siguiente: como enseña santo Tomás, a quien siguen los teólogos salmantinos en su teoría de la determinación, una vez que la autoridad ha especificado los requerimientos indeterminados del derecho por naturaleza, ya no es indiferente que esto sea de tal o cual modo. Debe ser así y no de otra forma ${ }^{84}$.

La ley humana puede, además, regular y limitar la traslación del dominio

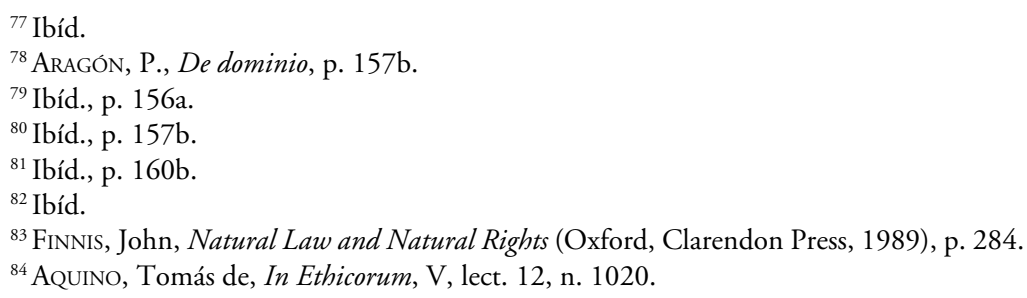


contra la propia voluntad de los dueños ${ }^{85}$. Tal es el caso de la prescripción, en donde la autoridad es libre para imponer ciertas restricciones al derecho natural del dueño para disponer de sus bienes según su voluntad ${ }^{86}$. Porque, en efecto, quien, poseyendo de buena fe durante el tiempo señalado por la ley, retenga los bienes de otro comportándose como señor y dueño, se hace propietario, por el sólo ministerio del derecho, de los bienes que originariamente pertenecían a otro $^{87}$. Y así, porque las leyes humanas, que obligan en conciencia, no sólo pueden mandar que uno entregue sus bienes a otro, sino también transferir el dominio a otro contra la voluntad del propietario ${ }^{88}$, quienes son favorecidos por la prescripción se hacen legítimos dueños de los bienes poseídos de buena fe, no porque se busque sancionar al primero de los titulares, sino, simplemente, porque en razón del bien común es necesario que exista certeza y seguridad en cuanto a las titularidades jurídicas.

\section{CONCLUSIONES}

Al cierre de este trabajo sobre la determinación del derecho natural en la obra de Pedro de Aragón, me parece posible presentar las siguientes conclusiones:

$1^{\circ}$ Las normas que resultan del acto de determinación, "que son como conclusiones de los principios naturales" ${ }^{89}$, entregan concreción y aplicabilidad a los preceptos de la recta razón, y son tan necesarias para la vida social, que, sin ellas, los principios del derecho natural no podrían cumplirse con facilidad.

$2^{\circ}$ En estas leyes, la razón humana no descubre una relación de necesidad, sino sólo de utilidad y conveniencia ${ }^{90}$. Esto porque se trata de principios que regulan materias que no están mandadas o prohibidas por el derecho natural, como lo ceremonial, según los ejemplos de los pensadores salmantinos, y que son inmediatamente obligatorias por causa de la voluntad del gobernante.

$3^{\circ}$ La afirmación de que el acto de determinación representa, en alguna medida, un opus voluntatis, me parece un acierto por parte de Aragón. El propio Aquinate, al hablar de la naturaleza de la ley, reconoce la tarea de la voluntad en la determinación de lo que es bueno moralmente en el ámbito de lo indiferente $^{91}$. Luego, supuesto que la tarea de creación del derecho se ejerce dentro de los

${ }^{85}$ Barrientos, J., El tratado “De justitia et jure”, cit. (n. 17), p. 244.

${ }^{86}$ Aragón, P., De dominio, p. 163b.

${ }^{87}$ Ibíd., p. 165b.

${ }^{88}$ BarRientos, J., El tratado "De justitia et jure", cit. (n. 17), p. 245.

${ }^{89}$ ArAGÓN, P., De justitia et jure, q. 85, a. 1. Con la expresión "conclusiones", Aragón no está indicando que las leyes positivas se obtengan deductivamente desde los principios naturales, sino sólo que las reglas de la justicia legal también son "derivaciones" de la ley natural, tal como las normas del derecho de gentes. De hecho, y en este mismo artículo, escribe Aragón que las leyes positivas se derivan del derecho natural como determinaciones o aplicaciones de sus principios más generales a situaciones concretas.

${ }^{90}$ Peña, J., De justitia, q. 57, a. 2, ms. T19.

${ }^{91}$ Aquino, T., Summa theologiae, I-II, q. 90, a. 1. Para un estudio de este problema, véase: Contreras, Sebastián, La "ratio legis" en la teología de Suárez y Santo Tomás. Una propuesta de comparación, en Teología y Vida, 43 (2012), pp. 507 ss. 
márgenes de lo naturalmente razonable, la elección que hace la autoridad entre las distintas alternativas disponibles es, ineludiblemente, un acto de su voluntad ${ }^{92}$.

$4^{\circ} \mathrm{La}$ determinación no sólo facultad al gobernante para completar el derecho natural; sobre todo le permite perfeccionarlo. Aragón se refiere a este problema cuando habla del cambio aditivo de la ley natural. En este sentido, lo que Aragón llama "perfección de la ley natural" no es otra cosa que la adición a los preceptos naturales de, por ejemplo, ciertas circunstancias o requisitos de validez de los actos jurídicos por parte de los legisladores humanos ${ }^{93}$.

$5^{\circ}$ A diferencia de las normas naturales, que son por esencia invariables ${ }^{94}$, las leyes que resultan de la determinación dependen del consenso, en el sentido de que tratan acerca de lo que en principio no interesa que sea de tal o cual manera, pero que sí interesa una vez que ha sido regulado por el legislador ${ }^{95}$. Esto hace que Aragón se oponga a las ideas de los protestantes. En opinión de los reformadores, no es posible que las autoridades humanas determinen lo que no está ya presente en las normas del derecho divino o en las Escrituras. Así lo entendió Lutero, quien arrojó públicamente a las llamas muchas bulas pontificias y libros de derecho canónico, y que, en opinión de Aragón, habría hecho algo todavía peor con las leyes del derecho civil o positivo si es que no hubiese "temido más a la espada secular que a la excomunión del papa" ${ }^{\prime 6}$.

$6^{\circ}$ Queda fuera de toda duda que las autoridades humanas pueden establecer principios de justicia que obliguen hasta el punto de que su trasgresión sea considerada como una forma de injusticia. La razón es que, como enseña Aragón, las potestades humanas serían vanas e inútiles si no tuvieran la fuerza necesaria para obligar en conciencia con sus determinaciones ${ }^{97}$. Ahora bien, cuando se habla de la obligación en conciencia de las leyes humanas, cabe preguntar inmediatamente si puede la ley humana no obligar en cuanto a culpa. A nadie se le escapa que el legislador "quiera limitarse a aconsejar o a decretar sin imponer obligación alguna;

${ }^{92}$ De ahí que FInNis, John, The Truth in Legal Positivism, en FInNIs, John, Philosophy of Law (Oxford, Oxford University Press, 2011), p. 177, haya indicado que, en lo que concierne a la elección que hace la autoridad al momento de dar una ley positiva, nada le obliga a decidirse por X en vez de Y.

${ }^{93}$ Pese a esto, es preciso hacer la siguiente aclaración: Aragón propone una distinción (al menos lingüística) entre mutación y perfección de la ley. Propiamente hablando, una ley se cambia cuando se abroga, esto es, cuando se suprime o se anula el contenido de justicia impuesto por esa determinación. En cambio, una ley se perfecciona cuando se le añaden ciertas circunstancias que la hacen más honesta y de mayor utilidad para la regulación de la vida social y política. Ahora bien, en opinión del agustino, sólo el segundo de estos movimientos puede afectar al derecho natural, el cual se completa y perfecciona a través de las normas positivas. El cambio, en estricto rigor, no procede en los preceptos morales.

${ }^{94}$ Aragón, P., De justitia et jure, q. 57, a. 2.

95 Ibíd.

${ }^{96}$ Ibíd.

${ }^{97}$ Ibíd., q. 85, a. 1. 
pero debe reconocerse que, en tal caso, no se está propiamente ante una ley"98. Porque, como sostiene el agustino, allí donde no hay obligación, no existe ley ${ }^{99}$.

$7^{\circ}$ Por último, el cometido de las leyes positivas, que "son sólo determinaciones particulares de lo que mandan los principios de la ley natural de modo universal" ${ }^{100}$, es la dictación de lo que es justo en un gobierno dado y para un tiempo concreto, según lo que sea de mayor utilidad para el bien común y para el cumplimiento del derecho por naturaleza ${ }^{101}$. En este sentido, a pesar de que las leyes humanas intenten completar el orden de moralidad presupuesto en la ley natural, no pueden extenderse a la prohibición de todos los vicios, por ejemplo. $\mathrm{Y}$ así, en ocasiones, pueden permitir la realización de acciones prohibidas por el derecho natural, porque, de acuerdo con las circunstancias de la comunidad de que se trate, lo que conviene más para el logro de la paz social y la seguridad pública es la no represión de esos males ${ }^{102}$.

\section{BiBLIOGRAFÍA}

Aquino, Tomás de, Opera omnia (Roma, Commissio Leonina, 1989) [edición crítica dirigida por los Padres Predicadores].

ARAgón, Pedro de, In secundam secundae Divi Thomae doctoris Angelici commentariorum (Salamanca, 1584), I.

Aragón, Pedro de, In secundam secundae Divi Thomae doctoris Angelici commentaria. De justitia et jure (Salamanca, 1590).

Barrientos, José, La Escuela de Salamanca: desarrollo y caracteres, en La Ciudad de Dios, 208 (1995).

BARRIENTOS, José, Repertorio de moral económica (1536-1670) (Pamplona, EUNSA, 2011). Barrientos, José, La injusticia en los juicios según Pedro de Aragón, en CruZ, Juan (editor), La justicia y los juicios en el pensamiento del Siglo de oro (Pamplona, EUNSA, 2011).

Barrientos, José, El tratado “De justitia et jure” (1590) de Pedro de Aragón (Salamanca, EUSAL, 1978).

BeLDa Plans, Juan, La Escuela de Salamanca y la renovación de la teología en el siglo XVI (Madrid, Biblioteca de Autores Cristianos, 2000).

${ }^{98}$ Jericó, Ignacio, Fray Pedro de Aragón. Un salmantino del siglo XVI (Madrid, Agustiniana, 1997), p. 78.

${ }^{99}$ Aragón, P., De justitia et jure, q. 85, a. 1.

${ }^{100}$ Ibíd., q. 57, a. 3.

${ }^{101}$ Jericó, I., Fray Pedro de Aragón, cit. (n. 98), p. 76. Por eso, en opinión del salmantino, excepcionalmente las leyes humanas podrán, en justicia, privar a los ciudadanos de sus bienes o impedirles adquirir el dominio de aquellas cosas que no tienen.

${ }^{102}$ Aragón, P., De justitia et jure, q. 62, a. 5. Esto no significa que exista alguna virtud que no tenga materias susceptibles de ser reguladas por la ley humana. Al contrario, precisamente porque el bien de cada virtud es referible al bien de la comunidad, es que las leyes humanas, en teoría, podrían regular los actos de todas las virtudes, lo que no ocurre, porque aquello equivaldría a salirse del campo de las potestades de la propia autoridad civil. Véase: BARRIENTOS, J., El tratado "De justitia et jure", cit. (n. 17), p. 129. 
Carpintero, Francisco, Justicia y ley natural: Tomás de Aquino, y los otros escolásticos (Madrid, Publicaciones de la Universidad Complutense, 2004).

CARRÓ, Venancio, La teología y los teólogos-juristas españoles ante la conquista de América (Salamanca, Biblioteca de Teólogos Españoles, 1951).

CONTRERAS, Sebastián, Los teólogos agustinos del siglo XVI sobre la "derivatio per modum determinationis": Juan de Guevara, Luis de León y Pedro de Aragón, en Cuestiones Teológicas, 40 (2013).

Contreras, Sebastián, Santo Tomás y la doctrina de la determinación del derecho. Análisis de los textos tomistas, en Ciencia Tomista, 140 (2013).

Contreras, Sebastián, La "ratio legis" en la teología de Suárez y Santo Tomás. Una propuesta de comparación, en Teología y Vida, 43 (2012).

CONTRERAS, Sebastián, La derivación del derecho positivo desde el derecho natural en Tomás de Aquino. Un estudio a partir de "Summa Theologiae" y "Sententia Libri Ethicorum”, en Teología y Vida, 54 (2013).

Corpus Christi, Mancio, De dominio, en Persona y Derecho, 12 (1985) [edición bilingüe latín-español de Augusto Sarmiento].

FINNIS, John, Natural Law and Natural Rights (Oxford, Clarendon Press, 1989).

FInNIS, John, The Truth in Legal Positivism, en FInNIS, John, Philosophy of Law (Oxford, Oxford University Press, 2011).

Guevara, Juan de, In secundam secundae, ms. T2, Biblioteca Universidad de Coímbra.

Guevara, Juan de, Textos jurídicos agustinianos. De homicidio et justitia commutativa. De justitia et iure (manuscritos de Fr. Juan de Guevara) (Madrid, San Lorenzo del Escorial, 1957) [edición de Bonifacio Difernan].

Guevara, Juan de, La fe, la esperanza y la caridad. Comentarios teológicos salmantinos (1569-1572) (Madrid, Agustiniana, 2009) [edición de Ignacio Jericó].

HeRVADA, Javier, Reflexiones acerca de la prudencia jurídica y el derecho canónico, en Revista Española de Derecho Canónico, 16 (1961).

Horst, Ulrich, Papst, Konzil, Unfehlbarkeit. Die Ekklesiologie der Summenkommentare von Cajetan bis Billuart (Mainz, Matthias-Grünewald, 1978).

IBÁÑEZ, Andrés, La doctrina sobre la tradición en la Escuela Salmantina (siglo XVI) (Vitoria, Editorial Eset, 1967).

Jerico, Ignacio, Desde la infidelidad hasta la justificación. Enseñanzas de Luis de León, Pedro de Aragón y Domingo Báñez (1569-1584) (Madrid, Agustiniana, 2010).

Jericó, Ignacio, La Escuela de Salamanca del siglo XVI (Madrid, Agustiniana, 2005).

Jericó, Ignacio, La fe católica en los salmantinos del siglo XVI. Fray Luis de León, Juan de Guevara y Pedro de Aragón (Madrid, Agustiniana, 1999).

Jerico, Ignacio, Fray Pedro de Aragón. Un salmantino del siglo XVI (Madrid, Agustiniana, 1997).

León, Luis de, De legibus. Tratado sobre la ley (Madrid, San Lorenzo del Escorial, 2005) [edición bilingüe latín-español de José Barrientos y Emiliano Fernández].

López, José María, Doctrina de fray Pedro de Aragón acerca de la ley humano-positiva y efectos obligatorios de la ley penal, en Anuario de Derecho Penal y Ciencias Penales, 2 (1949).

Molina, Luis de, Los seis libros de la justicia y el derecho (Madrid, Cosano, 1944) [edición de José Fraga Iribarne].

Pena, Miguel Anxo, La Escuela de Salamanca. De la Monarquia hispánica al Orbe católico (Madrid, Biblioteca de Autores Cristianos, 2009).

PeñA, Juan de la, De justitia, ms. T19, Biblioteca Universidad de Coímbra. 
PeÑA, Juan de la, In secundam secundae, ms. 333-53, Biblioteca de Sevilla.

PENÁ, Juan de la, In secundam secundae, ms. 1852, Biblioteca Universidad de Coímbra. RAmírez, Santiago, El derecho de gentes. Examen crítico de la filosofía del derecho de gentes desde Aristóteles hasta Francisco Suárez (Madrid, Stvdivum, 1955).

RIAZA, Román, La Escuela española de derecho natural, en Universidad, 2 (1995).

Soto, Domingo de, De justitia et jure libri decem. De la justicia y el derecho en diez libros (Madrid, Instituto de Estudios Políticos, 1967-1968) [edición bilingüe latín-español de Marcelino González].

TACK, Theodoro, Fray Pedro de Aragón, OSA. His Life, Works, and Doctrine on Restitution (Chicago, Augustinian Press, 1957).

Vitoria, Francisco de, De justitia. Über die Gerechtigkeit (Stuttgart, FrommannHolzboog, 2012) [edición bilingüe latín-alemán de Joachim Stüben].

Zorroza, Idoya, Fundamentos morales del contrato y de la propiedad en Domingo de Soto, en CRUZ, Juan (editor), La ley natural como fundamento moral y jurídico en Domingo de Soto (Pamplona, EUNSA, 2007). 
